http://jmscr.igmpublication.org/home/ ISSN (e)-2347-176x ISSN (p) 2455-0450 crossref DOI: https://dx.doi.org/10.18535/jmscr/v8i1.05

\title{
Comparative Study of two High Dose Rate Intraluminal Brachytherapy Schedules in Locally Advanced (Unresectable) CA Esophagus
}

\author{
Authors

\section{Dr Ranjeet Ram Jat ${ }^{1}$, Dr Neeti Sharma ${ }^{2 *}$, Dr H.S. Kumar ${ }^{3}$,} \\ Dr S.L. Jakhar ${ }^{4}$, Dr Pukhraj Sadh ${ }^{5}$
}

${ }^{1}$ Resident Doctor, Radiation Oncology Department, ATRCTRI, S.P. Medical College, Bikaner ${ }^{2}$ Professor and Head, Radiation Oncology Department, ATRCTRI, S.P. Medical College, Bikaner ${ }^{3}$ Senior Professor, Radiation Oncology Department, ATRCTRI, S.P. Medical College, Bikaner ${ }^{4}$ Associate professor, Radiation Oncology Department, ATRCTRI, S.P. Medical College, Bikaner

${ }^{5}$ Resident Doctor, Radiation Oncology Department, ATRCTRI, S.P. Medical College, Bikaner *Corresponding Author

\section{Dr Neeti Sharma}

Professor and Head, Radiation Oncology Department, ATRCTRI, S.P. Medical College, Bikaner

\begin{abstract}
Purpose of the study was to assess local tumor control and overall survival, diffirence in acute toxicities, and dysphagia free survival among two HDR intraluminal brachytherapy schedules for unresectable esophageal cancer. A total of 50 patients of locally advanced unresectable ca esophagus were taken for the study from January 2018 to February 2019. All patients were histological proven cases. All 50 patients were treated with CTRT (EBRT $44 \mathrm{~Gy} / 22 \#, 2 \mathrm{~Gy} / \#$, l\#/day, 5 days a week + weekly CT (cisplatin $40 \mathrm{mg} / \mathrm{m}^{2}$ ). Then followed by 2-3 weeks of gap 25 patients of this 50 were randomized on one to one basis to each Arm (Arm A and B). In arm A (6Gy/\# total 2\#, biweekly schedule) and arm B (4Gy/\# total 3\#, biweekly schedule).

All patients tolerated treatment well, no major adverse effects were monitored in two groups. There was no significant statistical difference in treatment response, which was found $84 \%$ vs $88 \%$ in 6 Gy arm and $4 G y$ arm respectively.however toxicity profile, was slightly higher in 6Gy arm. The 6 months DyFS were 52\% and $68 \%$ in $6 G y$ arm and $4 G y$ arm respectively;( $p$ value >.05). Overall survival were slightly higher in $4 G y$ arm in compare to 6 Gy arm (96\%vs92\%).

Keywords: Intraluminal brachytherapy, high dose rate, dysphagia free survival ,locally advanced carcinoma esophagus.
\end{abstract}

\section{Introduction}

The incidences of Esophageal carcinoma are increasing at its fast pace. As it is aggressive in nature and has very poor survival rate. Esophageal cancer exhibits an epidemiologic pattern distinct from all other cancers. The incidence of esophageal adenocarcinoma has increased sharply over the past few decades, both by period and birth cohort. ${ }^{1}$ Understanding the epidemiology of Esophageal carcinoma will be the key to elucidating the causes and risk factors for esophageal cancer and thus the cornerstone of developing any prevention strategies. ${ }^{1}$ 
In various retrospective studies of Esophageal cancer, smoking, hot tea drinking, red meat consumption, poor oral health, low intake of fresh fruit and vegetables, and low socioeconomic status have been associated with a higher risk of esophageal squamous cell carcinoma. Tobacco and alcohol consumption are the primary causes of squamous cell carcinoma (SCC) of the esophagus. One of the strongest emerging risk factors, however, is obesity. ${ }^{2}$

In our institute Acharya Tulsi Regional Cancer Treatment and Research Institute there is continuous rising trend in the number of esophagus cancer patients. In 2017-18 total 518 patients (M-284, F-234) and total 609 patients(M$329, \mathrm{~F}-280$ ) cases of esophageal cancer resistered in 2018-19.

Primary treatment for localized esophageal cancer is radical excision but in majority of cases the tumor is in advanced stage and already involves in the esophageal wall. The current standard of care for inoperable esophageal cancer is concurrent chemoradiation with 50.4 Gy radiotherapy and cisplatin/ 5-FU-based chemotherapy ${ }^{3}$. Further dose escalation to improve the outcome is limited critical surrounding structures. HDRILBT offers a simple, inexpensive method of conformal radiation therapy in this context of dose escalation with minimum morbidity. HDRILBT allows the escalation of dose to the oesophagus while protecting dose-limiting structure which is not possible even with the most conformal method of EBRT. In the definitive chemoradiation treatment of carcinoma oesophagus, role of brachytherapy remains unclear and investigational ${ }^{4}$. Most of the studies are single centre experiences and done in palliative setting to relieve dysphagia.

\section{Material and Methods}

This was a randomised prospective study conducted at Acharya Tulsi Regional Cancer Treatment And Research Institute, Sardar Patel Medical College and associated group of hospitals, Bikaner.
The study protocol include 50 patients of histologically proven unresectable locally advanced carcinoma esophagus. Who were enrolled from Jan 2018 to Feb 2019. Inclusion criteria included inoperable, locally advanced, tumor length $<10 \mathrm{~cm}$, histologically proved carcinoma of esophagus patients, ECOG performance status 0-2. Age 18-70 years, without any haematological, cardiac, renal or liver function abnormality, no previous history of treatment for esophageal cancer and no any other concurrent malignancies.

All 50 patients were received concurrent chemoradiation (EBRT 44Gy/22\#, 2Gy/\#, $5 \# /$ week + weekly inj. Cisplatin $40 \mathrm{mg} / \mathrm{m}^{2}$ ), after this patients were randomly assigned to two arms for ILBT HDR schedules either arm A (6Gy/\#, 2\# twice a week)or arm B (4Gy/\#, 3\# twice a week). Patients (both study groups) receiving concurrent chemoradiation $\mathrm{f} / \mathrm{b} \quad 2-3$ weeks of HDR brachytherapy (biweekly schedule) were accessed 2-3weeks after completion of CTRT (44Gy+weekly CT) for local disease response. Treatment response was assessed by UGIE, Barium Swallow, USG neck and CECT thorax \& abdomen.

Hematological \& renal function test were evaluated weekly during treatment. Patient with anemia or poor general condition received fresh blood transfusion and buildup therapy. Symptomatic treatment was given in patient suffering from side effects of chemotherapy. Patient were evaluated for dysphagia at 1, 3 and 6 month. A barium swallow was done in the first and third month. UGIE was done at 3 month for disease assessment and biopsy was done when indicated. USG \& CECT of chest and abdomen was obtained if any clinical suspicion of either local recurrance or metastasis. Toxicity was graded as per RTOG/EORTC criterias. 


\section{Results:}

Tables: Patients characteristics

\begin{tabular}{|c|c|c|}
\hline Patients characteristics & Arm A & Arm B \\
\hline \multicolumn{3}{|l|}{ Age (in years) } \\
\hline Median age & $59 \mathrm{yr}$ & $52 \mathrm{yr}$ \\
\hline Range & $35-79$ yrs & $35-77$ yrs \\
\hline \multicolumn{3}{|l|}{ Sex } \\
\hline Male & 14 & 13 \\
\hline Female & 11 & 12 \\
\hline \multicolumn{3}{|l|}{ ECOG } \\
\hline 1 & 18 & 19 \\
\hline 2 & 7 & 6 \\
\hline \multicolumn{3}{|l|}{ Tumor stage } \\
\hline T3 & 17 & 16 \\
\hline $\mathrm{T} 4$ & 8 & 9 \\
\hline \multicolumn{3}{|l|}{ Nodal stage } \\
\hline N0 & 6 & 2 \\
\hline N1 & 7 & 8 \\
\hline N2 & 10 & 13 \\
\hline $\mathrm{N} 3$ & 2 & 2 \\
\hline \multicolumn{3}{|l|}{ Group stage } \\
\hline Stage III & 11 & 15 \\
\hline Stage IV & 14 & 10 \\
\hline \multicolumn{3}{|l|}{ Anatomical site } \\
\hline Upper thoracic & 2 & 1 \\
\hline Middle thoracic & 19 & 18 \\
\hline Lower thoracic & 4 & 6 \\
\hline
\end{tabular}

Table 2: Treatment response at 1 month

\begin{tabular}{|cc|c|c|}
\hline \multirow{2}{*}{ Treatment response @ 1 month } & \multicolumn{2}{|c|}{ Number of patients } \\
\cline { 3 - 4 } & & Arm A (25) & Arm B (25) \\
& & $100 \%$ & $100 \%$ \\
\hline Regressive disease & CR & $9(36 \%)$ & $12(48 \%)$ \\
& PR & $16(64 \%)$ & $13(52 \%)$ \\
Total & & & \\
\hline Stable disease & & $25(100 \%)$ & $25(100 \%)$ \\
\hline Progressive disease & & 0 & 0 \\
\hline
\end{tabular}

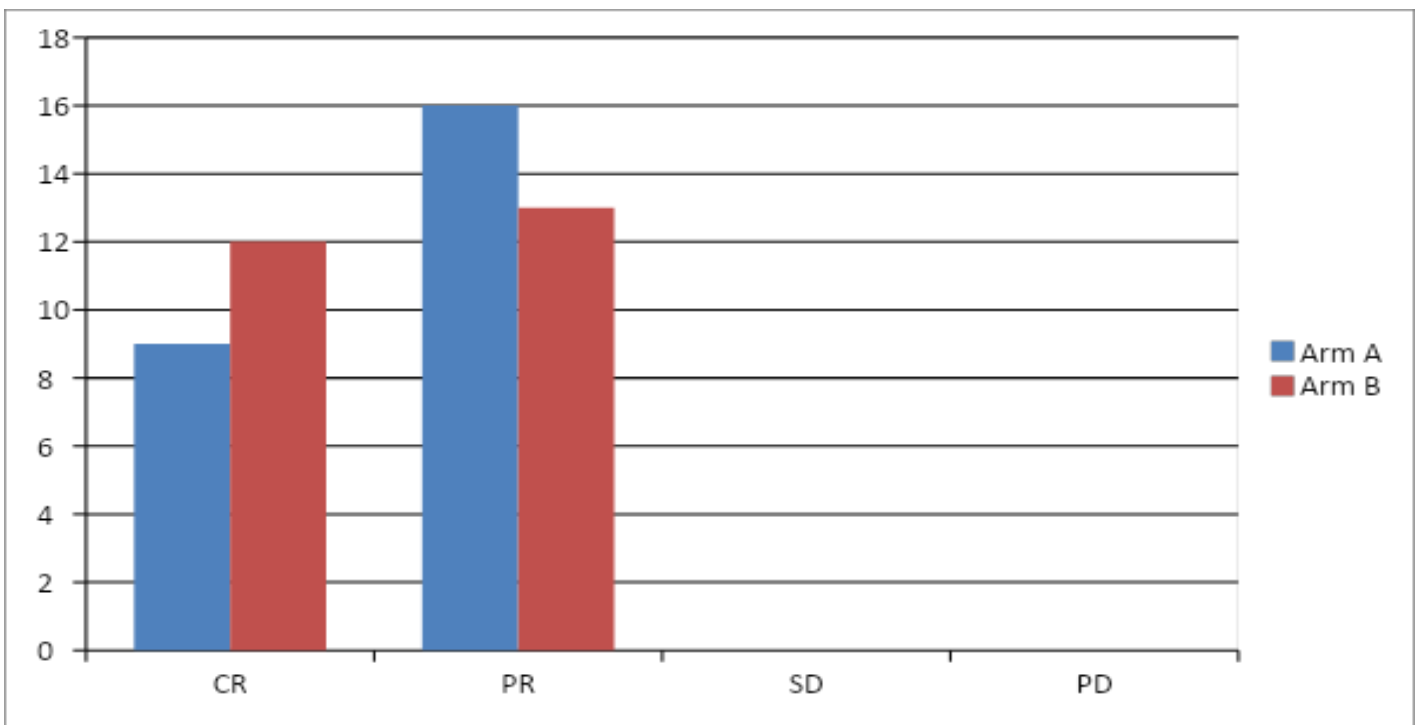


Table 3: Treatment Response at 3 months

\begin{tabular}{|c|c|c|}
\hline \multirow[t]{2}{*}{ Treatment response @ 3 months } & \multicolumn{2}{|c|}{ Number of patients } \\
\hline & $\begin{array}{c}\text { Arm A (25) } \\
100 \%\end{array}$ & $\begin{array}{c}\text { Arm B (25) } \\
100 \%\end{array}$ \\
\hline $\begin{array}{ll}\text { Regressive disease } & \mathrm{CR} \\
\mathrm{PR}\end{array}$ & $\begin{array}{l}15(60 \%) \\
10(40 \%)\end{array}$ & $\begin{array}{l}17(68 \%) \\
7(28 \%)\end{array}$ \\
\hline$(\mathrm{CR}+\mathrm{PR})$ & $25(100 \%)$ & $25(100 \%)$ \\
\hline Stable disease & 0 & 0 \\
\hline Progressive disease & 0 & 0 \\
\hline
\end{tabular}

Table 4: Treatment Response at 6 months

\begin{tabular}{|c|c|c|}
\hline \multirow[t]{2}{*}{ Treatment response@6 months } & \multicolumn{2}{|c|}{ Number of patients } \\
\hline & $\begin{array}{c}\text { Arm A (25) } \\
100 \%\end{array}$ & $\begin{array}{c}\text { Arm B (25) } \\
100 \%\end{array}$ \\
\hline $\begin{array}{lc}\text { Regressive disease } & \text { CR } \\
& \text { PR }\end{array}$ & $\begin{array}{l}21(84 \%) \\
4(16 \%)\end{array}$ & $\begin{array}{l}22(88 \%) \\
3(12 \%)\end{array}$ \\
\hline$(\mathrm{CR}+\mathrm{PR})$ & $25(100 \%)$ & $25(100 \%)$ \\
\hline Stable disease & 0 & 0 \\
\hline Progressive disease & 0 & 0 \\
\hline
\end{tabular}

Table: 5 Prevalence of dysphagia

\begin{tabular}{|l|c|c|c|}
\hline & $\begin{array}{c}\text { FOLLOW UP AT ONE } \\
\text { MONTH }\end{array}$ & $\begin{array}{c}\text { FOLLOW UP AT THREE } \\
\text { MONTH }\end{array}$ & $\begin{array}{c}\text { FOLLOW UP AT SIX } \\
\text { MONTH }\end{array}$ \\
\hline ARM A & 23 & 18 & 12 \\
\hline ARM B & 21 & 16 & 11 \\
\hline
\end{tabular}

Table 6: Pain relief at follow up

\begin{tabular}{|l|c|c|c|}
\hline & pain relief at one month & pain relief at three month & pain relief at six month \\
\hline Arm A & 10 & 15 & 21 \\
\hline Arm B & 12 & 17 & 23 \\
\hline
\end{tabular}

Table 7: Incidence of acute toxicities after completion of treatment

\begin{tabular}{|l|c|c|c|c|c|}
\hline Toxicities & ARM & Grade 1 & Grade 2 & Grade3 & Grade4 \\
\hline VOMITING & $\mathrm{A}$ & 07 & 18 & 00 & 00 \\
\cline { 2 - 6 } & $\mathrm{B}$ & 09 & 16 & 00 & 00 \\
\hline \multirow{2}{*}{ HEMATOLOGICAL } & $\mathrm{A}$ & 08 & 01 & 00 & 00 \\
\cline { 2 - 6 } & $\mathrm{B}$ & 05 & 01 & 00 & 00 \\
\hline \multirow{2}{*}{ RENAL } & $\mathrm{A}$ & 01 & 00 & 00 & 00 \\
\cline { 2 - 6 } TOXICITY & $\mathrm{B}$ & 01 & 00 & 00 & 00 \\
\hline
\end{tabular}

Table 8: Stricture formation as a late complication

\begin{tabular}{|l|c|c|}
\hline Stricture & Arm A & Arm B \\
\hline Yes & $05(20 \%)$ & $04(12 \%)$ \\
\hline No & $20(80 \%)$ & $21(84 \%)$ \\
\hline
\end{tabular}




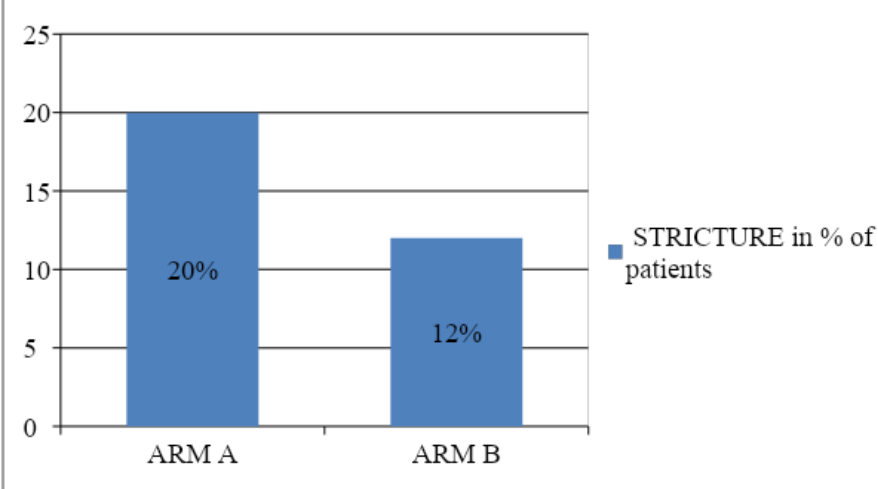

Patients had ECOG performance status 1\&2, median age $59 \& 52$ yrs (arm A \& arm B), both gender, stage III \& IV of locally advanced esophageal cancer in both arms. During the treatment none of the patient lost from follow up or expired in both arms. Total 25 patients were received complete treatment in each arm.

The follow up was done at 1 month after completion of ILBT HDR, 09 and 12 patients had complete response in arm A \& arm B for any stage ( $p>.05)$; which was insignificant. Although all patients had regression ( $p>.05$ ). The 6 months PFS were $100 \%$ in both arms.

There was no any grade3 \& 4 hematological \& nonhematological toxicities were found in both arms. The symptoms relief in respect to dysphagia and pain were better in arm B, which was statistically insignificant.

Late complications were more in arm A. Stricture formation $20 \%$ in arm A and $12 \%$ in arm B, but $p$ value insignificant.

\section{Discussion}

In present study total 50 patients, histologically proven, were enrolled and treated with EBRT in both arms and then they were treated with two schedules of brachytherapy. All the patients showed good response to CTRT, though grade I and II hematological, vomiting and renal toxicities were seen, but no grade III toxicities were noted in both arms and all patients completed their schedule without interruption. Western studies however reported grade III and IV toxicities (30\%-58\%) and poor compliance, $64 \%-70 \%$, to treatment that might be due to higher doses with brachytherapy schedule.

Across the both schedules dysphagia were initially high in both arms but subsided as time lapsed. But dysphagia again increased at six month but that was not significant, might be due to small number of sample size.

We also inquired for pain relief at local site subjectively which was relieved in both arms and relief was increased during the time after treatment. All patients had a partial response locally after external radiation. The complete response rate was $36 \%$ in ARM A and $48 \%$ in $\mathrm{ARM} \mathrm{B}$ at one month follow up. LC rates were $84 \%$ and $88 \%$ in ARM A and ARM B respectively after a median follow-up of 06 months, but those differences were not statistically significant. These results were comparable with previous studies. In RTOG 92-07 trial ${ }^{5}$, in which patients were treated with 50 Gy EBRT followed by $2 \#$ of brachytherapy with

$5 \mathrm{~Gy} / \#$ and LC rate was noted as $73 \%$. A study by Calais et al., ${ }^{6}$ in which 60 Gy conventional external radiation was given concurrent with Cisplatin, 5-flourouracil, and Mitomycin followed by two sessions of ILBT 5 Gy each, reported LC rates of $74 \%$ at 1 year. This later came down to $57 \%$ at 3 years. This indicates that chemoradiation schedules with brachytherapy boost are feasible but require a careful selection of patients with a good KPS, along with a need of further studies to standardize HDR ILBT schedules with chemoradiation protocols.

In our study the stricture formation was the commonest complication and it was high, $20 \%$ in $\mathrm{ARM} \mathrm{A}$, and It was low in ARM B, 12\% (P value $=0.4404$, not significant) .Ulceration was seen in two patients in ARM A but not in ARM B. All strictures were negative for malignant cells on endoscopic biopsies and cytology. While Kapoor R. et al. $^{7}$ noted that $\mathrm{LC}$ rates were $67 \%$ with 6Gy/\# arm and $89 \%$ with $4.67 \mathrm{~Gy} / \#$ arm and major complications like ulceration and trachea esophageal fistulas were more often seen with a higher dose per fraction of the brachytherapy 
schedule. Our results were comparable with this study.

There has been few clinical trials using brachytherapy as boost and reporting data on feasibility, tumor control, and associated toxicities. The present study has several limitations. The study is structured with small number of patients and short follow up period. A multivariate and with large sample size, study is required to conclude a optimal dose fractionation for ILBT.

\section{Conclusions}

On assessment and result evaluation the results in respect of CR, LC, Dy FS rate were slightly better in 4Gy arm at 1 month, 3 months, 6 months but not statistically significant.

The overall survival rate were slightly higher in 4Gy arm.

Pain relief was more in arm B (4Gy/\#) at local site subjectively.

There were no significant differences in the incidence of acute toxicities in both radiation schedules however stricture formation was higher in arm A (20\%) and in arm B (12\%).

In patients with unresectable carcinoma esophagus, concurrent chemoradiation followed by an ILBT boost is feasible with an acceptable toxicity profile and good LC rates with increased risk of complications is seen with the higher dose per fraction of brachytherapy (6 Gy $\times 2 \#)$.

Further prospective clinical studies with large number of patients and longer follow up is required to define dose schedules.

\section{References}

1. Esophageal cancer: epidemiology, pathogenesis and prevention. Nat Clin Pract Gastroenterol Hepatol 2008; 5: 517-526 [PMID: 18679388 DOI: 10.1038/ncpgasthep1223])
2. Hareyama M, Nishio M, Kagami $Y$, Narimatsu N, Saito A, Sakurai T. Intracavitary brachytherapy combined with external beam irradiation for squamous cell carcinoma of the thoracic esophagus. Int $\mathrm{J}$ Radiat Oncol Biol Phys 1992;24:235-40.

3. Sun De-Ren. Ten year follow up of esophageal cancer treated by radical radiation therapy: Analysis of 869 patients. Int J Radiat Oncol Biol Phys 1989;16:329-34.

4. Vauthey JN, Maddern GJ, Gertsch P. Cesar Roux - Swiss pioneer in surgery Surgery. 1992; 112:946-50.

5. Gaspar LE, Winter K, Kocha WI et al. A phase I/II study of external beam radiation, brachytherapy, and concurrent chemotherapy for patients with localized carcinoma of the esophagus (Radiation Therapy Oncology Group Study 9207): final report. Cancer 2000; 88: 988-995

6. Calais G, Dorval E, Louisot P, Bourlier P, Klein V, Chapet S, et al. Radiotherapy with high dose rate brachytherapy boost and concomitant chemotherapy for stages IIB and III esophageal carcinoma: Results of a pilot study. Int $\mathbf{J}$ Radiat Oncol Biol Phys 1997;38:769-75.

7. Kapoor R, Bansal A, Kochhar R, Kumar P, Sharma SC. Effectiveness of two high-doserate intraluminal brachytherapy schedules for symptom palliation in carcinoma esophagus: A tertiary care center experience. Indian J Palliat Care 2012;18:34-9. 